\title{
Advances and visions in large-scale hydrological modelling Proceedings of the 11th Workshop on Large-scale Hydrological Modelling
}

\author{
F. Portmann ${ }^{1}$, K. Berkhoff ${ }^{2}$, and M. Hunger ${ }^{3}$ \\ ${ }^{1}$ Institute of Physical Geography, University of Frankfurt, Germany \\ ${ }^{2}$ Institute of Environmental Planning, Leibniz University Hanover, Germany \\ ${ }^{3}$ Ingenieurbüro Dr.-Ing. Karl Ludwig, Karlsruhe, Germany
}

In 1998 the German Universities of Kassel and Giessen organised a workshop on water and solute transport in large drainage basins. The workshop focused on analysing and summarising the state of research, existing problems and perspectives in this research area. It was the second of a series of annual workshops since 1997 that became an important discussion forum for the German-speaking research community in the field of hydrological modelling. Now the 11th Workshop on Large-scale Hydrological Modelling ${ }^{1}$ referred to the same questions as posed in 1998 in order to evaluate the developments and advances of the last ten years. Based on keynote presentations, the workshop focused on discussion in working groups where also posters were presented. This volume of "Advances in Geosciences" comprises seven papers referring to the poster contributions. At the end of the volume, an overview paper summarises the outcome of the workshop presentations and discussions (Döll et al.). The individual contributions are ordered along the topics that were discussed:

1. Sensitivity of model results to input data and spatial discretisation

(Barthold et al., Petersen et al., Weiß and Menzel, Zhang and Döll, Zhang et al.)

2. Approaches to integrated modelling (Schmalz et al.)

3. Coupling of processes in hydrosphere, atmosphere, and biosphere (Rost et al.).

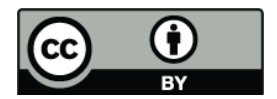

Correspondence to: F. Portmann

(portmann@em.uni-frankfurt.de)

1 Held from 31 October to 2 November 2007 in KelkheimEppenhain.
The editorial team would like to thank Nadine Deisel of Copernicus Publication Office for agreeing to publish this issue and for the smooth publication process. We equally thank the authors and the reviewers of the submitted papers for their motivation and cooperation. With this volume, we hope to reflect the breadth of the interesting discussions of the workshop.

\section{Outline}

- Barthold, F. K., Sayama, T., Schneider, K., Breuer, L., Vaché, K. B., Frede, H.-G., and McDonnell, J. J.: Gauging the ungauged basin: a top-down approach in a large semiarid watershed in China

- Petersen, G., Bast, H., and Fohrer, N.: Estimation of ungauged Bahr el Jebel flows based on upstream water levels and large scale spatial rainfall data

- Weiß, M. and Menzel, L.: A global comparison of four potential evapotranspiration equations and their relevance to stream flow modelling in semi-arid environments

- Zhang, J. and Döll, P.: Assessment of ecologically relevant hydrological change in China due to water use and reservoirs

- Zhang, X., Hörmann, G., and Fohrer, N.: An investigation of the effects of model structure on model performance to reduce discharge simulation uncertainty in two catchments

Published by Copernicus Publications on behalf of the European Geosciences Union. 
- Schmalz, B., Bieger, K., and Fohrer, N.: A method to assess instream water quality - the role of nitrogen entries in a North German rural lowland catchment

- Rost, S., Gerten, D., and Heyder, U.: Human alterations of the terrestrial water cycle through land management
- Döll, P., Berkhoff, K., Bormann, H., Fohrer, N., Gerten, D., Hagemann, S., and Krol, M.: Advances and visions in large-scale hydrological modelling: Findings from the 11th Workshop on Large-scale Hydrological Modelling 